\title{
MIGRATION AND NARRATION
}

\section{Brigitte Boenisch-Brednich}

The following article aims to work out the main narrative techniques of "telling migration". The conclusions drawn on the subject of migration and narration are based on a one-year field work study, combining participant observation with interviewing. This study took place in New Zealand concentrating on German immigrants between 1936 and 1996. The main source for my analysis given in this paper is provided by 102 people I interviewed. The texts of these biographically-focussed interviews allowed me to work not only on an ethnographical history of migration but also to gain insights into peoples' experiences, and over and above that, to learn what kind of stories and techniques of storytelling emigration creates. The book focuses on a comparatively wide time frame of sixty years (BoenischBrednich 2001). This makes it possible to analyse very different periods of migration and groups of migrants, contrasting social categories as well as exploring differences in education, milieu, age and gender. Furthermore, it becomes obvious that although all migrants were leaving Germany and arriving in New Zealand, they experienced what were in effect very different countries through time - different Germanys, different New Zealands. To work out the changing reasons for migrating (work migration, refuge, global lifestyle, etc.) inside western societies is a major theme the book is aiming for.

A second approach is to investigate migration from the perspective of focussing on everyday life, an investigation on the basis of personal experiences, such as "work, housing, food, celebrations, social life". A special focus is set on the analysing of "mental narratives" as key stories, examples, comparatives etc.

The central questions of this project were: What kind of strategies do people use to cope with a major changes in their biography, as constituted by emigration? What does integration really mean and how does it work for different groups? What kind of collective and individual stories does migration create? In which ways does retroperspection work as a technique for creating autobiographies in oral transmission?

http://www.folklore.ee/folklore/vol20/brednich.pdf 
Immigration is a central and natural part of New Zealand history and therefore a very important part of peoples' identity. It seems to be crucial to know where you or your ancestors came from, to be able to identity yourself in New Zealand and in your overseas ancestry. Therefore the conclusions I draw from my material point towards general insights into the migration process, not just with regard to specifically German experiences. I will point out some German specialities, but will mostly try to give some general conclusions as to how the process of telling the narratives of migration seems to work in the individual biographical frame.

One of the major criticisms on the leading theoretical discussion about migration and the process of globalisation (as by James Clifford, Arjun Appadurai or Homi Bhabha) is that hardly any of their theories are based on examples derived from research. Most of what is said about modern thinking and acting in a so-called global world, is based on guesswork (Welz 1998), and therefore partly reflects the world views of the academics writing about the subject. So, one of my aims was to provide material which allows reality-based analysis of the changing pictures of migration in the 20th century. And I deliberately chose a group of people who do not come from a third world country to a highly industrialised one. I wanted to be free from those aspects of political correctness which dominate the theory -, and so be free to observe and to draw conclusions without being bound to analysing social problems.

In short, I wanted to have a look at a privileged country giving people to another privileged country and therefore getting insights into a kind of globalisation inside the western world we can understand because its strongly comparable to our own experiences.

What has emerged is a picture of the step by step process of the conceptualising of modern mobile cultures, and their embeddedness in the history of belief systems of migration and the self-definitions of migrants. With the interview material I can analyse how personal decisions about emigration are connected to political, economical, ecological and social backgrounds. This doesn't exclusively relate to the strict New Zealand rules of immigration. It also applies to such matters as changing belief systems and social strata. For example the Green Movement led to a new kind of migration phenomenon. Or the rising numbers of single women migrating 


\section{Brigitte Boenisch-Brednich}

and travelling the world can be seen as a result of the women's movement, and therefore grounded in the 'liberation of female biographies'. So how people are structuring their individual biographies is strongly linked with their social and cultural environment. A good example of that is the recent immigration of middle-aged people with money-savings to places as Provence, Mallorca or New Zealand. They indicate the migration of the well-off and therefore the end of the full working society, a society which is no longer based on full employment, but on early retirement with golden hand shakes on the side of people being able to follow up the luxury emigration scheme.

Because my research was aimed at investigating the different periods of emigration as well as aspects of individual experiences I worked out two interwoven lines of argumentation, combining these aspects into an ethnographic approach on migration. You could call this: What actually happened, and how do people talk about it?

\section{THE PROCESS OF EMIGRATION TO NEW ZEALAND BETWEEN 1936 AND 1996}

The classic reasons for migration used to be flight, exile and work migration. In the course of the 20th century up to the $1990 \mathrm{~s}$, emigration from Western Europe gradually became a phenomenon targeting personal lifestyle rather than outward driven reasons such as the ones just mentioned. Migration became an individual decision, driven by the intention to construct a successful satisfying biography; it became no longer a matter of surviving or just making a suitable living. To a certain degree you could even say that the phenomenon "emigration" is disappearing, because it is not a final decision anymore. It is part of a biographical item to structure your life into the so called "patchwork biographies" of modern lives (Hitzler \& Hoher 1994). Migration is just one of the options available, and the word itself is replaced in migrants conversation by expressions like "moving" and "changing places". These so called "movings" are increasingly strongly linked to preceding holidays, where a likely place to migrate would be carefully chosen. For example, people would visit Ireland, Canada, Australia and New Zealand in holidays before deciding about the place to go. Or - in my 
cases - one couple which was really in love with Scotland, finally decided on a similar place with slightly better weather conditions: Stewart Island, an island south of the South Island of New Zealand with a very "scottish" climate.

Migration for West-European people today is connected to lifestyle decisions and therefore strongly linked to Pierre Bourdieus' concept of habitus. With the integration of the modern lifestylish concept of "moving" you either demonstrate a modern biographical openness or the capacity for handling your cultural, social, economical and ecological capital (when Bourdieu developed his concept of habitus and cultural capital it was too early to integrate the concept of "ecology" as a distinctive lifestyle in it, but it is important today). New Zealand is one of the chosen paradise places for Europeans, and this is even more the case because of the strict limitations its Government has set up for immigration. Getting permanent residence requires either good education or wealth and is therefore bound to be exclusive. Permanent residency is a privilege of higher milieus and therefore a valuable part of modern lifestyle biographies. Migration as a biographical 'option' (in the sense in which Ralf Dahrendorf uses the word) is - in the 1990s - part of your biographical choices in the creation of your patchwork-CV. When sociologists such as Ulrich Beck talk about investigating modern lives, they always point out what the diagnosis of research about modern lives is, that they are based on the necessity of making your own decisions, creating your individual mental map and being the director of the script of your own special yearly CV-programme (Beck \& Beck-Gernsheim 1993).

The strong positive emphasis our recent society puts on mobility makes it an important part of biographies and the planning and visions involved in the processes of lives. Mobility, the wish for mobility, and the pressure to appear mobile, as well as touristy patterns and real migration-proceedings, are therefore important subjects for research about modern identities and biographies. Identity research is mainly done by interview techniques. And it is seen as a fact by the academics doing the research that the work of constructing identity and biography through the process of story telling is an everyday task which is merely strongly focussed in an interview situation. Therefore it is necessary to find out about the narratives 


\section{Brigitte Boenisch-Brednich}

of people to be able to get a picture of the state of modern identities. The narratives of emigrants in short tell you what migration means, how people deal with it, and in which special modes of narratives their stories are formed.

The individual history of migration in an interview appears as a string of well-formed narratives, interrupted by periods of consideration, thinking about unexpected questions, and the virtuoso presentation of key narratives which the person has developed in the course of his or her migration history. Migration as a turning point in the biography is transformed into a personal narrative, and therefore parts of it have to be constantly repeated - perhaps reinvented to place this important turning point into its proportions in the life narrative.

\section{HOW MIGRATION IS NARRATED}

Migration is part of an autobiographical narrative which is never told as a whole, but emerges in short entities, connected to stimulation that arises in conversations.

In my material you can see relatively clear generational differences in the self-construction of migration histories. You may say that the process of migration in the narratives is either finalised or still open, and this makes an important difference in the stories being told. How this works is dependent on the point in the biography in which the migration occurred. The immigrants of the periods between 1936 to 1952 spent most of their adult lives in New Zealand. Germany is connected with the first quarter of their lives, with childhood and early adulthood and often with trauma. Most of the emigrants have not visited Germany for many years, if ever. The stories about Germany and the initial migration are therefore finalised and told as complete vignettes. Discussion about leaving, arriving, integration, often end in a final statement: "New Zealand was good to me". This positive perspective is derived from having lived here for more than five decades, having children and grandchildren being New Zealanders and leaving a Germany vastly different from that of today. The migration took place so long ago that it is a point of certainty in the narrative of the biography. 
This pattern is quite similar insofar as the emigrants of the $1950 \mathrm{~s}$ and 1960s are concerned; they also look back on emigration as a finalised and successful project in earlier life. The decision to stay in New Zealand was made a long time ago. They too have lived more then half of their lives here, and their professional career, as well as their family period, took place here. Therefore a relatively big distance has been created between their country of origin and their everyday lives. However, contacts remain, as do future plans for visiting and receiving visitors. This repertoire of telling stories about two countries, and comparing them, is still an open process and therefore more material for narratives will be produced. The subject Germany versus New Zealand is one with actuality.

For the immigrants of the last ten years, the decision and the actual step of migrating is part of the very recent past; it is still a definitely open story. Life in Germany is a big pool of life experience and reflection, while New Zealand is a new territory with a limited number of experiences and, therefore, stories. Talking about New Zealand is therefore strongly connected with talking about the process of migration. Long reflections about how the decision was finally made, and what actually happened in the process of leaving and arriving, are central subjects. Overcoming bureaucratic and organisational hurdles, as well as money problems, parting from relatives and friends and - very important - the acquisition of a new house in New Zealand are significant matters to reflect on. Migration is an open project, applying itself to everyday life and matters integrating into a still new or even strange country. The difference in the attitude towards migration compared to that of previous migrants lies in the different words used to describe what they did. Many of the recent immigrants don't even use the word emigration anymore. They say "we moved to Auckland, the Bay of Islands, Takaka etc." The term "moving" as an equivalent term for migration implies possibilities of moving on, of an open future, especially for young migrants. This openness in the planning and constructing of the future is strongly connected to the offers of mobility that dominate modern western society, and again with the sketching out of individual plans for the future. 
Brigitte Boenisch-Brednich

\section{THE PROCESS OF MEMORISING AND NARRATING MIGRATION}

Besides trying to work out different periods of migration and different levels of experience, I was especially interested in hearing and searching for stories which are told about the general experience of going to another culture and living in there. Generally, one can say that special experiences are remembered as being crucial in the whole process of going to New Zealand. These are key narratives, they have been told often, and they are well structured, polished and ready for presentation at any time. They are "Ready-Mades"1.

In terms of migration experiences there are 3 types of narrative items: a) Stories about leaving and arriving, b) stories about the first year in New Zealand, which are stories about cultural misunderstanding, language problems, homesickness; basically about feeling alien, and being considered alien. And c) there is a form of narratives covering the whole life of a migrant: the narratives of comparing countries and cultures - the culture you come from and the one you are now living in.

I guess nearly everybody has stories in mind which fit in these three categories, but I will give some examples to illustrate them.

The narratives of the very first impressions on New Zealand are vivid and mostly very short. Most of what is remembered is told as an inner dialogue, just watching and trying to form the new experience into some words. Ester Einhorn, a Jewish Refugee, said about her arrival in Wellington:

We came into Wellington Harbour on 10 July 1939. It was a wonderful sunny morning, the Orongorongos were covered with snow. It was beautiful and I thought I was in Switzerland. I had never been in Switzerland and that was exactly as I always imagined it. And then at midday it started raining and rained - I thinkright up to Christmas.

The first impressions, beside taking in the new landscape, were mostly those of the different food, the missing coffee-shops, the Sundays when everything was closed. But sometimes it was pleas- 
Migration and Narration

urably different, as Peter Munz pointed out in the story of his first breakfast in Christchurch 1940:

On our first morning in Christchurch, in January, we had breakfast on the veranda of our friends' house. And for the first time in my life I ate Weet Bix.2. And I said to myself, oh a country which is offering me something so wonderful, must be good for me. I liked that so much and that was how it all started: with Weet Bix.

The archetype of the story of the first year surely is "Bring a plate" or "Ladies a Plate". ${ }^{3}$ It is more than a story, I think we could call it a hidden rites de passage. Women had to go through it, but did not know in advance that it would happen - although it is a common experience of arriving. For women it appears in the stories like a double shock. They misunderstood the language - and brought an empty plate rather than food - and therefore failed in a point crucial for their life: preparing food. The embarrassment when they turned up with an empty plate, was an open one, and it happened in front of members of the new culture, making it an even bigger event than stories of normal misunderstandings which mostly happen as a not outspoken experience - or at least are not openly realised by a whole group of people.

An example of such a "normal story", similar to "bring a plate" is the following one, Edith told me about her first year in the 1960s:

When I was here in the beginning, I was quite lonely. The children were in school, Andrew was at work. And then in the Supermarket I met this women who lived just down the road from us. We had a chat and then she said. "Well, I see you later." And I rushed home tidied everything up and waited for her. And finally in the afternoon I said to myself. 'Well, that is incredibly unkind of her to say she would see me later and not even ringing me to call that off'.

The underlying system of all these stories is the overall scheme of constantly comparing countries. Comparing is something we used to talk about a lot as a method of thinking and working in social sciences and humanities. But very little emphasis is actually put on looking at it as an every day practice of reflecting and talking. One 


\section{Brigitte Boenisch-Brednich}

of my interviewees put this fact into a remarkable sentence by pointing out that:

If a meaningful period of your life took place in a different cultural frame, you are bound to compare it up to the end of your life.

I consider it as crucial for its points of interests to find out about this type of narrative and how it works as an everyday technique of putting such stories into the life experience.

In the process of composing points to compare, people create a supposedly objective reality; this enables them to combine argumentation and narration, and to make sense of their world. That comparing is the basic technique of most of the stories is not always obvious to the people listening and neither to the narrator. Quite often immigrants give a kind of an individual ethnography of New Zealand society, but don't talk about their own cultural background. In describing "The Other" you take yourself for granted as a ground of objectivity. Janet Frame, the famous New Zealand writer, saw that very clearly when she sat off for her first journey overseas and wrote from Curacao: "I was aware of 'the other country' comparison [..] And here I was, travelling overseas to 'broaden my experience' and already undergoing the change forced on every new traveller and accomplished by examining not the place of arrival but the place of departure" (Janet Frame in King 2000).

These stories about the other culture / speak the "strange New Zealanders" in the eyes of immigrants, are far from being one-dimensional or straight forward. They outline pictures showing very different, often incoherent patterns to the outsider; only the migrant him- or herself can bring it to a pattern which makes sense for him- or herself.

A good example of one such contradictory subject is that of New Zealand as a supposedly classless society. So, in one interview somebody could emphasise the egalitarian structures of New Zealand society, for example that you may have friends here both plumbers and doctors, or housewives and opera singers; always implying that Germany is highly class structured, in contrast. But in the same interview, he would start talking about the conservative South Is- 
Migration and Narration

land city of Christchurch: the nobility of the descendants of the first immigrant ships, about private schools and old boys networks. It has to fit into the line of the conversation about classlessness, however: New Zealand can be both in theses stories: class-ridden within its classlessness; but Germany stays the same. Very often the stories on comparing countries are based on experiences the immigrants had while being back in Germany for a holiday.

Needless to say that for the migrants I interviewed (they all stayed in New Zealand) all play the comparing battle with a clear outcome. New Zealand wins, Germany is nearly always going to loose in straight sets. The tales used in order to play the game are sometimes moral, quite often bitter and ironic, and sometimes really drastically funny. Comparing countries can be told as a humorous anecdote, a narrative with living pictures outlining a comedy. One of these stories deals with the description of a weekend out on a boat, having fun sailing.

Jan Lehmann: "Lets just compare the matter of sailing: in Germany on the river Elbe (which goes through Hamburg and later into the North Sea). Well you want to go for a weekend trip from Hamburg to the sea. Well this is boring in the first place because the whole river has been lined up with dams. And when there is no wind you have to motor, which means you have to bring up a black triangle at starboard. And when you want to anchor you have to put up an anchor ball. And when you don't need to cruise you have to keep on starboard. Otherwise the water police charges you for that. And for the lamps you need a two year warranty and all this is so horrible. And here, people are sailing without warranties. I haven't got lamps on my ship, I don't even have an anchoring ball. And I can fish as much as I want to. Oh what I can do here its fantastic, and all of that I am not allowed in Germany. I can't even go to the beach in Germany without paying an entrance fee. It drives me mad even thinking of it!"

Comparing countries can also mean that people are drawing very personal conclusions about their life in both countries. They compare their German biography and personality, with their changed characters in New Zealand. Quite often they say that going through the difficult process of emigration, experiencing loneliness, isolation and different culture, means that their personality changed. 


\section{Brigitte Boenisch-Brednich}

They gained more inner freedom, more confidence in themselves and in their ability to master the future. They also describe themselves as less German, more relaxed, less fixed on materialism and on the pressures of consumerism. But New Zealand society has taken big steps in the recent past towards matters they have left behind, and so comparing biographies is especially important for recent immigrants (the last 15 years). Because their decision to leave Germany is driven by the strong wish for a different lifestyle, and not caused by problems of unemployment or political pressures. They push the rational narrative to points of proving their decision was right, because they feel right even though New Zealand society has been moving in a materialistic direction. A very personal decision is therefore followed by creating individual narratives which underline the direction in which they have sought to change their biographies. A direction which may be contradicted by the actual society around us.

Up to now I have dealt with "Ready-Mades", easily and perfectly presented in the interview, because they have been worked out and told before. But not all narratives are Ready-Mades. Ready-Mades in interviews are accompanied by silence, half sentences and uneasy stories told for the first time or changed by an unexpected question. There are topics people don't really want to talk about in an interview, or if asked they try to avoid a clear answer. One of these topics is naturally the question of immigration history which hasn't come out to be totally successful, or even lead to unhappiness. Conflicts as for example when the emigration led to a marriage breaking up, or to an end to a promising professional career are very carefully painted out, avoided or glossed over. The emigration needs to be considered as a success otherwise life in the eyes of themselves and the world would probably be impossible to enjoy. A good example for such a careful self-description is the following narrative about how one of my interviewees starts his every day routine. He lives in a remote house in Golden Bay, ${ }^{4}$ having left his family and his job, and he has turned to a bohemian lifestyle on his own:

Every day I start balancing myself into looking out to the Tasman Sea and tell myself how happy and privileged I am to be able to 
Migration and Narration

live here. Well it is important to tell myself every day, otherwise it can turn into a dead bore to be here. What else can I do?

But this is more the exception, maybe $10 \%$ per cent of my interviews revealed this slightly problematic pattern of trying to narrate success when you should really be talking about misfortune or failure. The usual way is that a key narrative is used as a personal and symbolic mark ${ }^{5}$ to give a rationale as to why one stayed in New Zealand and still think of it as the better place to live - for indeed the decisions are generally rational and it has turned out to be a good place to live. According to everything I said up to now, it is predictable that people, being asked why they stayed, do not answer with statistics about clear air, less pollution, less bureaucracy or something like that. They answer with a story which contains most of what they cherish in New Zealand, but in a more personal and symbolic way. A good example is the following story about coming back from Germany, being still on the airport and learning why it is so good to be back:

Geli: "We are back in New Zealand. Our son Enno, then five years old, disappeared into this bookshop at the national airport. And my husband Dirk followed him up. But Enno had obviously already pinched a lolly and had started sucking it too. Dirk became nervous and said, 'Stop that I have to pay for that first'. And started hectically searching for New Zealand money. Then a chap turned round and said: 'Don't worry mate, I fixed that'. It was David Lange having bought a lolly for our son. Well, that can only happen in New Zealand, that the Prime Minister is hanging around on an airport and buys a lolly for a kid. It is typical, its really just happening here, funny, eh?"

With this anecdote the interviewee proves her decision for New Zealand to be right; the young women, her son and the prime minister become part of a story describing the country's virtues where humanity and social skills are part of the everyday culture. Such key narrations express very complex experiences inside people's immigrant biography.

So coming back to my introduction, I think it emerges very clear that the main narratives of immigration are "Ready-Mades" that assure immigrants about their life in the new country. Stories of 


\section{Brigitte Boenisch-Brednich}

unsurity are told to emphasise the arrival period and the problems during the time. Stories of failures and unhappiness or uneasiness are not likely to be told, especially not in public. The narratives on immigration are narrated to assure a standard of emotional safety, a coming to positive terms with the big change emigration represents in a personal biography.

\section{IS THERE SOMETHING LIKE A NATIONAL (IMMIGRANT) NARRATIVE?}

New Zealand being a country of immigrants, it is an immigrant nation. I believe it could be a fruitful academic line of thinking whether there might be a reservoir of immigrant narratives that New Zealanders as a nation prefer to tell. Maybe there are existing "Ready-Mades" New Zealanders like to tell about themselves and their young country - to ensure their identity and to create a feeling of safety about having found this place in the South Pacific. And if so, what would be the narratives unlikely to be told, the ones which might reveal failure, uneasiness and mishaps.

I have a suspicion, that in the New Zealand perspective at least, the story of "Bring a Plate" is one - in some circumstances at least - of putting newcomers in the right place, of knowing that the ones who have been here already know the rules and their way around. Therefore "Bring a Plate" in the eyes of the observing and laughing New Zealanders is really a story of feeling safe. But it would be challenging to look out for the narratives of much more fundamental significance. What strikes me as an overall topic of great importance that New Zealanders talk about is the question "Who came first". The narratives of the first canoes, the first ships, of assuring special groups of people the right to be here and to stay here is a crucial story that is told. One could probably say that narratives are so important for everyday life, for persons, for groups and for nations because they give a comforting assurance about our existence. They can provide pictures of our lives and the society around us in a way that can be neatly framed. But these narratives represent just one set of pictures, others are stored away in the family linen cupboard, seldom to emerge in public. 
Migration and Narration

\section{Comments}

${ }^{1}$ A term used Keupp et al. (1999), changing a term, originally describing art installations, on to the art of telling individual narratives.

2 This is a breakfast cereal.

${ }^{3}$ This was a very common form of having parties and social functions. The invitation would read "Ladies a plate, men a bottle", meaning that everybody should bring some food and drink. But European immigrant women misunderstood countless times and brought jus empty plates or just one big serving plate with nothing on it. A situation which is strongly linked to embarresment and shame and therefore a topic for storytelling.

${ }^{4}$ A remote region on the South Island of New Zealand.

${ }^{5}$ Key narrative is used in connection with Sherry Ortners (1973) definition of key symbols.

\section{References}

Beck, Ulrich \& Beck-Gernsheim, Elisabeth 1993. Nicht Autonomie, sondern Bastelbiographie. Zeitschrift fuer Soziologie 3, pp. 178-187.

Boenisch-Brednich, Brigitte 2001. "Keeping a low profile". An ethnography of German immigration to New Zealand, 1936-1996. Wellington: Victoria University Press.

Hitzler, Ronald \& Hoher, Anne 1994. Bastelexistenz. Über subjektive Konsequenzen der Individualisierung. Riskante Freiheiten. Individualisierung in modernen Gesellschaften. Beck, Ulrich \& Beck-Gernsheim, Elisabeth (eds.). Frankfurt am Main, pp. 307-315.

Keupp, Heiner \& Ahbe, Thomas \& Gmür, Wolfgang 1999. Identitaetskonstruktionen. Das Patchwork der Identitaeten in der Spaetmoderne. Reinbeck bei Hamburg: Rowohlt-Tasckenbuch-Verlag.

King, Michael 2000. Wrestling with the Angel.A Biography of Janet Frame. Auckland: Picador, Macmillan.

Ortner, Sherry B. 1973. Key Symbols. American Anthropologist 75, pp. $1338-1346$.

Welz, Gisela 1998. Moving Targets. Feldforschung unter Mobilitaetsdruck. Zeitschrift für Volkskunde 94, pp. 177-194. 